\title{
Octogenarians in the catheterization laboratory
}

\section{Kristina Marić Bešić*, Zoran Miovski, Maja Strozzi}

University of Zagreb School of Medicine, University Hospital Centre Zagreb, Zagreb, Croatia

\section{RECEIVED:}

February 5, 2016

ACCEPTED:

February 20, 2016

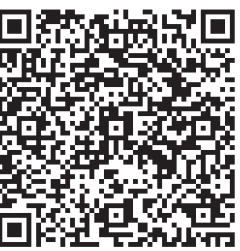

$\square$ Cardiologia Croatica 2016:11(3-4):102.
KEYWORDS: octogenarians, percutaneous interventions.

CITATION: Cardiol Croat. 2016;11(3-4):102. | Dol: http://dx.doi.org/10.15836/ccar2016.102

*ADDRESS FOR CORRESPONDENCE: Kristina Marić Bešić, Klinički bolnički centar Zagreb, Kišpatićeva 12, HR-10000 Zagreb, Croatia. / Phone: +385-91-233-6805 / E-mail: kmaricbesic@gmail.com

ORCID: Kristina Marić Bešić, http://orcid.org/0000-0002-4004-72 • Zoran Miovski, http://orcid.org/0000-0002-3850-8905 Maja Strozzi, http://orcid.org/0000-0003-4596-8261

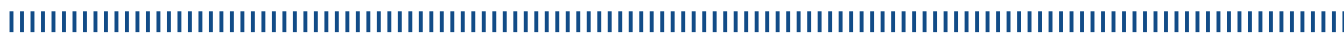

The number of octogenarians undergoing percutaneous procedures has increased in the past years as a consequence of demographic changes. According to data $25 \%$ of all percutaneous coronary interventions (PCI) are performed in patients over the age of 75 and $12 \%$ in those aged over 80 years. There is not only a higher incidence of acute coronary syndrome (ACS), but also an increase of patients with stable angina and transcatheter aortic valve implantation (TAVI) procedures. The elderly have more comorbidities, multivessel disease, complex lesions and therefore a higher incidence of post procedural complications. ${ }^{1,2}$

We present an overview of percutaneous interventions in octogenarians preformed in our catheterization laboratory from 2011 until 2015. The aim was to investigate indications, procedure success, periprocedural complications, intrahospital mortality and 1 year survival rate.

There were 762 patients, 417 (55\%) male and 345 (45\%) female. The majority of patients 448 (58.8\%) had an ACS; ST-segment elevation myocardial infarction (149 or 19.5\%); non ST-segment elevation myocardial infarction + unstable angina pectoris ( 275 or $36 \%$ ) and cardiogenic shock or arrest (24 or 3.1\%). Stable angina was the indication in 143 (18.7\%) patients and elective PCI in 40 (5.2\%) patients. There is an increase for valvular disease evaluation from 5.6\% in 2011 to $16.5 \%$ in 2015. The majority of patients had 3-vessel disease 255 (33.0\%) and 170 (22.3\%) had previous PCI or coronary artery bypass grafting. Overall 380 (49.8\%) patients were treated (362 PCI, $18 \mathrm{TAVI}$ ). The success rate was $87 \%$ and the complication rate $5.1 \%$. Intrahospital mortality was $13.7 \%$ in the PCI group and $5.2 \%$ in the non-PCI group. A total of 495 (65\%) patients had a follow-up period of one year, 386 (50.6\%) were alive (171 PCI, 251 non-PCI).

In conclusion, the number of octogenarians in our catheterization laboratory is increasing. Although data from registries suggest that they appear to benefit in terms of quality of life after PCI, a careful approach to patient selection is essential to get the best outcomes.
LITERATURE IIIIIIIIIIIIIIIIIIIIIIIIIIIIIIIIIIIIIIIIIIIIIIIIIIIIIIIIIIIIIIIIIIIIIIIIIIIIIIIIIIIIIIIIIIIIIIIIIIIIIII

1. Singh M, Peterson ED, Roe MT, Ou FS, Spertus JA, Rumsfeld JS, et al. Trends in the association between age and in-hospital mortality after percutaneous coronary intervention: National Cardiovascular Data Registry experience. Circ Cardiovasc Interv. 2009;2(1):20-6. DOI: $h$ ttp://dx.doi.org/10.1161/CIRCINTERVENTIONS.108.826172

2. Bauer T, Möllmann H, Weidinger F, Zeymer U, Seabra-Gomes, Eberli F, et al. Predictors of hospital mortality in the elderly undergoing percutaneous coronary intervention for acute coronary syndromes and stable angina. Int J Cardiol. 2011;151(2):164-9. DOI: http://dx.doi.org/1016/j.ijcard.2010.05.006 